\title{
Pulmonary function testing as a diagnostic tool to assess respiratory health in bottlenose dolphins Tursiops truncatus
}

\author{
A. Borque-Espinosa ${ }^{1,2,3}$, F. Burgos ${ }^{4,5}$, S. Dennison ${ }^{6}$, R. Laughlin ${ }^{7}$, M. Manley ${ }^{7}$, \\ R. Capaccioni Azzati ${ }^{3}$, A. Fahlman ${ }^{1,2,8, *}$ \\ ${ }^{1}$ Research Department, Fundación Oceanogràfic de la Comunitat Valenciana, Valencia 46005, Spain \\ ${ }^{2}$ Research Group on Biomedical Imaging $\left(\mathrm{GIBI}_{2}{ }^{30}\right.$ ), Instituto de Investigación Sanitaria la Fe, Valencia 46026, Spain \\ ${ }^{3}$ Marine Biology Laboratory, Universitat de València, Valencia 46100, Spain \\ ${ }^{4}$ Department of Pulmonary Medicine, Hospital Clínic-Institut d'Investigacions Biomèdiques August Pi I Sunyer (IDIBAPS), \\ Universitat de Barcelona, Barcelona 08036, Spain \\ ${ }^{5}$ Center for Biomedical Network Research in Respiratory Diseases (CIBERES), Madrid 28029, Spain \\ ${ }^{6}$ TeleVet Imaging Solutions, PLLC, Oakton, VA 22124, USA \\ ${ }^{7}$ Siegfried \& Roy's Secret Garden and Dolphin Habitat, The Mirage, Las Vegas, NV 89109, USA \\ ${ }^{8}$ Global Diving Research Inc., Ottawa, ON K2J 5E8, Canada
}

\begin{abstract}
Pulmonary function testing was performed in 3 bottlenose dolphins Tursiops truncatus ( 1 female and 2 males) under managed care during a 2 yr period to assess whether these data provide diagnostic information about respiratory health. Pulmonary radiographs and standard clinical testing were used to evaluate the pulmonary health of each dolphin. The female dolphin (F1) had evidence of chronic pulmonary fibrosis, and 1 male (M2) developed pneumonia during the study. Pulmonary function data were collected from maximal respiratory efforts in water and from spontaneous breaths while beached. From these data, the flow-volume relationship, the flow measured between 25 and $75 \%$ of the expired vital capacity (mid forced expiratory flow, $\mathrm{FEF}_{25 \%-75 \%}$ ), and the percent of the vital capacity (VC) at the peak expiratory flow (\% $\left.\mathrm{VC}_{\mathrm{PEF}}\right)$, were evaluated and compared with the diagnostic assessment. For maximal respiratory manoeuvres in water, there were no differences in $\mathrm{FEF}_{25 \%-75 \%}$ or $\% \mathrm{VC}_{\mathrm{PEF}}$, and the flow-volume relationship showed a consistent pattern for F1. Additionally, $\mathrm{FEF}_{25 \%-75 \%}$ and $\% \mathrm{VC}_{\mathrm{PEF}}$ decreased by 27 and $52 \%$, respectively, and the flow-volume relationship showed clear flow limitations with emerging disease in M2. While spontaneously breathing on land, M2 also showed a $49 \%$ decrease in $\% \mathrm{VC}_{\mathrm{PEF}}$ and changes in the flow-volume relationship, indicating flow limitations following the development of pneumonia. Based on these preliminary results, we suggest that pulmonary function testing should be given more attention as a non-invasive and possibly adjunctive diagnostic tool to evaluate lung health of dolphins under managed care and in the wild.
\end{abstract}

KEY WORDS: Lung mechanics $\cdot$ Diving physiology $\cdot$ Marine mammals $\cdot$ Radiography $\cdot$ Diagnostic imaging $\cdot$ Spirometry $\cdot$ Pulmonary disease

\section{INTRODUCTION}

Respiratory disease is a major problem for cetaceans both in the wild and under managed care (Sweeney \& Ridgway 1975, Howard et al. 1983,

\footnotetext{
*Corresponding author: afahlman@whoi.edu
}

Baker 1992, Johnson et al. 2009, Bogomolni et al. 2010, Venn-Watson et al. 2012), where the clinical signs are often masked until the animal is severely affected. Methods to diagnose respiratory disease include computed tomography (CT), ultrasound, 
radiography, bronchoscopy, bronchoalveolar lavage (BAL), tracheal wash, blood and blow samples, and cytology (Reidarson et al. 1998, Sweeney \& Reddy 2001, Johnson et al. 2009, Smith et al. 2012, Ivančić et al. 2014, Martony et al. 2017). While CT may be the gold standard for diagnostic purposes and has been used in some cases, it is logistically challenging for these species. Portable ultrasound and radiography, on the other hand, are becoming more common, but both have limitations. The former can be done with the animal both in and out of the water, but due to the near-perfect reflection of the sound beam at tissueair interfaces, only the lung periphery can be evaluated (Smith et al. 2012, Martony et al. 2017). Radiography requires that the animal is on land, which causes lung compression in cetaceans like dolphins, which often weigh $200 \mathrm{~kg}$ or more. Additionally, for large animals, high X-ray exposure settings, multiple images, and orthogonal projections are necessary to cover the entire lung field (Van Bonn et al. 2001). Bronchoscopic intervention provides information about potential obstruction and allows the opportunity to obtain biopsies. Blow samples, tracheal washes, or BAL are used to perform cytology or culture the microbiome to assess airway disease. Together with blood samples, these tests provide key information about active disease and the type of infection, e.g. fungal or bacterial, but they do not provide immediate results or information about the functional changes.

Pulmonary function testing (PFT) is commonly used to assess lung health in humans (Crapo 1994, Miller et al. 2005, García-Río et al. 2013) and has been successfully used in the veterinary field to study pulmonary disease in terrestrial mammals of different sizes (McKiernan \& Johnson 1992, Rozanski \& Hoffman 1999, Hoffman 2002). This technique may be a useful diagnostic tool in marine species where it is logistically challenging to identify pulmonary disease and assess its progression with CT, radiographs, bronchoscopy, and ultrasound (Gans 2013, Fahlman et al. 2019a). Spirometric pulmonary function testing is performed by measuring the respiratory flow during one, or several, breathing manoeuvres. In humans, flow and volume limitations are evaluated by asking the patient to inhale fully to total lung capacity and then exhale forcefully (Miller et al. 2005, García-Río et al. 2013). A number of pulmonary function indices and the obtained flow-volume relationships are used to evaluate whether there are deviations from normal patterns.

In the current study, we used radiographs and clinical tests to evaluate respiratory health in 3 adult bottlenose dolphins Tursiops truncatus. The animals cooperated in pulmonary function testing in water and provided pulmonary function data for spontaneous and forced breaths, which were then compared with radiographs and clinical tests. The animals included in the study were 1 female dolphin with evidence of pulmonary fibrosis (F1), 1 male dolphin that remained healthy throughout the study (M1), and 1 initially healthy male that contracted pneumonia during the testing period (M2). The 2 male dolphins also participated in opportunistic pulmonary function testing while beached and spontaneously breathing.

\section{MATERIALS AND METHODS}

Three adult bottlenose dolphins (Table 1), housed at Siegfried and Roy's Secret Garden and Dolphin Habitat (Las Vegas, NV, USA), participated voluntarily in pulmonary function testing (spirometry) using a custom-built pneumotachometer (Mellow Design) (see Fig. 1 in Fahlman et al. 2015). Pulmonary function testing trials occurred twice per year between April 2017 and April 2019 (6 sampling periods). In total, 18 trials were performed in water, with the dolphins either breathing spontaneously or being asked to make maximal respiratory efforts. The 2 male dolphins also performed a total of 4 trials while beached for a medical procedure, and opportunistic data from spontaneous breaths were collected. Experimental protocols were approved by the Animal Care and Welfare Committee of Fundación Oceanogràfic in Valencia, Spain (OCE-17-16 and amendment OCE29-18) and by Siegfried and Roy's Secret Garden and Dolphin Habitat.

\subsection{Animals and training}

Before commencing the pulmonary function testing, the animals were trained using operant conditioning to be desensitized to the equipment (Fahlman

Table 1. Animal, sex $(\mathrm{M} / \mathrm{F})$, average $( \pm \mathrm{SD})$ body mass $\left(M_{\mathrm{b}}\right)$ measured within a week of each trial, straight length (rostrum to fluke notch, SL), and year of birth (YOB). The birth year of the female was unknown but estimated

\begin{tabular}{|lcccc|}
\hline Animal ID & Sex & $M_{\mathrm{b}}(\mathrm{kg})$ & SL $(\mathrm{cm})$ & YOB \\
\hline F1 & F & $231 \pm 8$ & 262 & 1975 \\
M1 & M & $186 \pm 8$ & 240 & 2011 \\
M2 & M & $177 \pm 4$ & 242 & 2011 \\
\hline
\end{tabular}


et al. 2015). This approach allowed for pulmonary function testing in dolphins in a relaxed and normal physiological state. Trials in water were performed through behavioural cooperation, and no dolphin was restrained during the experimental trial. For pulmonary function testing while beached, the 2 male dolphins voluntarily swam into a medical pool and the floor was lifted until the dolphin was out of water. Each trial in water or while beached consisted of 1 animal remaining stationary, allowing for placement of the pneumotachometer (spirometer) over the blowhole, and breathing spontaneously or being asked to make 4-5 maximal respiratory efforts (trained 'chuff') while continuous flow measurements were made.

\subsection{General health monitoring: routine clinical pathology}

To assess the health of each dolphin at the time of each pulmonary function testing, specific clinical samples were collected, analysed, and interpreted. Complete blood cell counts, serum chemistries (analysed at IDEXX Laboratories, NV, USA), sedimentation rates, and sputum cytology (analysed onsite by Siegfried and Roy's Secret Garden and Dolphin Habitat laboratory technician staff) were performed within $\pm 14 \mathrm{~d}$ of the spirometry exams.

\subsection{Radiography}

Thoracic radiographs were obtained on dolphins out of water. The 3 dolphins each voluntarily swam into a submerged stretcher, were manually lifted from the water, and placed in sternal and lateral recumbency during image acquisition. For each dolphin, numerous (11-20) radiographs were obtained using a portable X-ray unit (MinXRay TR90B; Canon CXDI-70C wireless digital radiography detector; or VetRocket X1 Portable DR system) as necessary to permit assessment of all lung fields. Orthogonal views were acquired for all animals and included dorsoventral and lateral projections obtained through vertical and horizontal beam techniques. No complications were observed following prompt return of each animal into the water. Following image acquisition, results were evaluated in an optimized environment using a commercially available, FDA-approved DICOM viewer (MacPro with Apple Thunderbolt Display; Osirix MD v.8.0.1, Pixmeo) by a board-certified veterinary radiologist (S. Dennison) with extensive experience in marine mammal diagnostic imaging. Radiographs were evaluated to determine whether the thorax, and specifically the pulmonary parenchyma and airways, were normal or abnormal. If abnormal, further characterization of the pattern present was classified as unstructured interstitial (a poorly organized change in the parenchyma), structured interstitial (nodular change), or alveolar (consolidation of a region or regions), patterns per veterinary radiographic interpretation convention.

\subsection{Spirometry tests and variables}

The procedures and equipment for measuring respiratory flow $(\dot{V})$, breath duration, and estimating tidal volume (VT) were identical to those used in a previous study on bottlenose dolphins (Fahlman et al. 2015).

To assess changes in respiratory function during disease, we evaluated the flow-volume relationship and defined 2 functional indices. One of these was the flow measured between 25 and $75 \%$ of the expired vital capacity (VC) or the mid forced expiratory flow $\left(\mathrm{FEF}_{25 \%-75 \%}, \mathrm{l} \mathrm{s}^{-1}\right.$ ) (Miller et al. 2005, García-Río et al. 2013). The second index was obtained from a variable used in human spirometry, the peak expiratory flow (PEF, $1 \mathrm{~s}^{-1}$ ) (Miller et al. 2005, GarcíaRío et al. 2013), but adjusted for the respiratory mechanics and capacity in dolphins (Fahlman et al. 2017): the percent of the expired VC at the PEF $\left(\% \mathrm{VC}_{\mathrm{PEF}}\right)$.

Mean $( \pm \mathrm{SE})$ air temperature, environmental pressure, and humidity during trials were $22.0 \pm 1.6^{\circ} \mathrm{C}$ ( $\mathrm{n}=22$, range $\left.12-20^{\circ} \mathrm{C}\right), 101.4 \pm 0.2 \mathrm{kPa}(100.2-$ $102.6 \mathrm{kPa})$, and $30.0 \pm 4.0 \%(9-42 \%)$. The average water temperature was $24.7 \pm 2^{\circ} \mathrm{C}\left(24-26^{\circ} \mathrm{C}\right)$.

\subsection{Data assessment and statistical analysis}

For experiments in water, the 3 maximal expiratory efforts of each trial were used to evaluate the flowvolume relationship and calculate $\mathrm{FEF}_{25 \%-75 \%}$ and $\% \mathrm{VC}_{\mathrm{PEF}}$. For beached trials, the flow-volume relationship of all voluntary breaths was obtained, and the 3 most similar manoeuvres were included for the analysis. To allow for comparable values between species, gas volumes were converted to standard temperature, pressure, dry (STPD) as in previous studies (Fahlman et al. 2015). 
All values are reported as means \pm SD, unless otherwise stated. Temporal changes in PFT variables (expired and inspired breath duration, $\dot{V}$, and VT) and indices $\left(\mathrm{FEF}_{25 \%-75 \%}\right.$ and \% $\left.\mathrm{VC}_{\mathrm{PEF}}\right)$ were assessed using generalized linear mixed (GLM) effects models ('lme', R version 3.6.1). Trial date and respiratory effort (voluntary or maximal/chuff) were considered as independent fixed covariates, and the individual animal was treated as a random effect. The multivariate statistical analysis was performed following the same criteria as in previous studies (Fahlman et al. 2019b), with significance based on the log-likelihood ratio test.

\section{RESULTS}

\subsection{Clinical cases summary: routine clinical pathology and radiography}

The female dolphin (F1) was previously diagnosed with chronic bronchitis and bouts of pneumonia through radiographs and routine clinical pathology (increased white cell count and sedimentation rate, and culture positive for Aspergillus spp.). During the experimental period, this dolphin presented with a chronic decreased serum iron. Additionally, unstructured interstitial abnormalities were identified on radiographs (Table 2), with the most applicable differentials being fibrosis, infection, or low-grade, chronic airway/parenchymal inflammation. However,

Table 2. Summary of radiographic pulmonary assessment for both lung fields for dolphins F1, M1, and M2 (see Table 1 for details of individual dolphins). NA: not assessed; N: normal; SI: structured interstitial; UI: unstructured interstitial

\begin{tabular}{|c|c|c|c|}
\hline \multirow[t]{2}{*}{ Date of radiographs } & \multicolumn{3}{|c|}{ Participating dolphin } \\
\hline & F1 & M1 & M2 \\
\hline July-August 2016 & UI & $\mathrm{N}$ & $\mathrm{N}$ \\
\hline February-March 2017 & $\mathrm{SI}^{\mathrm{a}}$ & NA & $\mathrm{N}^{\mathrm{a}}$ \\
\hline August 2017 & NA & NA & $\mathrm{N}$ \\
\hline October 2017 & NA & $\mathrm{N}^{\mathrm{a}}$ & NA \\
\hline January 2018 & NA & $\mathrm{N}$ & UI and SI \\
\hline May-June 2018 & $\mathrm{SI}^{\mathrm{b}}$ & NA & $\mathrm{UI}$ and $\mathrm{SI}^{\mathrm{a}}$ \\
\hline Jul 2018 & UI & NA & NA \\
\hline August 2018 & NA & NA & $\mathrm{UI}$ and $\mathrm{SI}^{\mathrm{a}}$ \\
\hline November 2018 & NA & NA & UI and SI \\
\hline January 2019 & NA & UI & $\mathrm{UI}$ and $\mathrm{SI}^{\mathrm{a}}$ \\
\hline March 2019 & NA & $\mathrm{N}^{\mathrm{a}}$ & NA \\
\hline \multicolumn{4}{|c|}{$\begin{array}{l}\text { andicates the radiographs taken } \pm 1-30 \text { d either before or } \\
\text { after the pulmonary function testing } \\
\text { b This animal underwent radiography after } 56 \mathrm{~d} \text { of the } \\
\text { pulmonary function testing }\end{array}$} \\
\hline
\end{tabular}

as the degree of change did not vary significantly in the following radiography evaluations, fibrosis was most likely, based on radiographs. Treatment administered previously (several years prior to study dates) and during the study period for a urinary tract infection and pulmonary disease included posaconazole (dosed at $\sim 3 \mathrm{mg} \mathrm{kg}^{-1}$ ) and Clavamox (dosed at $\sim 6 \mathrm{mg} \mathrm{kg}^{-1}$ twice a day).

The healthy male bottlenose dolphin (M1) had previously been diagnosed with suspected emerging pneumonia through thoracic radiographs (Spring 2016), that showed resolution of disease in July 2016. The white blood cell count, serum iron, sedimentation rate, fibrinogen, and blow cytology were within normal range during the study period. All radiographs performed were interpreted as normal, except for an emerging abnormal pattern interpreted as possible pneumonia in January 2019, which had radiographically resolved in March 2019 (Table 2). The dolphin was assumed symptom free but received voriconazole (dosed at $\sim 2 \mathrm{mg} \mathrm{kg}^{-1}$ once a day) from January until March following the radiographic findings.

Male dolphin M2 had previously been diagnosed with intermittent bronchitis and bouts of pneumonia that showed resolution of disease on radiographs in June 2016. During the experimental period, the erythrocyte sedimentation rate was within normal range, but was markedly increased $\left(60 \mathrm{~mm} \mathrm{~h}^{-1}\right.$, normal range 4-17 $\mathrm{mm} \mathrm{h}^{-1}$ ) in April 2018. Radiographs (Table 2) showed that both lung fields were normal throughout 2017, but unstructured and structured abnormalities, suggestive of pneumonia, were identified in both lungs in January 2018. Radiographs showed persistent pulmonary pathology with improvement on repeated studies in May and June, that radiographically worsened in August 2018, and improved at the end of 2018 and the beginning of 2019. The dolphin was treated for pneumonia from January 2018, beginning with voriconazole (dosed at $\sim 2 \mathrm{mg} \mathrm{kg}^{-1}$ once daily), which was switched to posaconazole (dosed at $\sim 4 \mathrm{mg} \mathrm{kg}^{-1}$ once daily) after 5 mo, when the animal showed persistent pulmonary pathology on chest radiographs.

\subsection{Spirometry in water}

While the dolphins were stationed in water, we collected a total of 122 spontaneous breaths (Table 3) and included 162 maximal respiratory efforts in the analysis (Table 4). For spontaneous breaths, there were no differences in inspiratory (insp) or expiratory 
Table 3. Animal ID, total number of collected breaths $(\mathrm{N})$, and averages $( \pm \mathrm{SD}, \mathrm{n}=6$ for each dolphin) of expiratory (Exp) and inspiratory (Insp) breath duration, respiratory flow $(\dot{V})$, and tidal volume (VT) for voluntary breaths in water

\begin{tabular}{|c|c|c|c|c|c|c|c|}
\hline \multirow{2}{*}{$\begin{array}{l}\text { Animal } \\
\text { ID }\end{array}$} & \multirow[t]{2}{*}{$\mathrm{N}$} & \multicolumn{2}{|c|}{ Breath duration (ms) } & \multicolumn{2}{|c|}{$\longrightarrow \dot{V}\left(1 \mathrm{~s}^{-1}\right) \longleftarrow$} & \multicolumn{2}{|c|}{$-\mathrm{VT}(\mathrm{l})-$} \\
\hline & & Exp & Insp & Exp & Insp & Exp & Insp \\
\hline F1 & 39 & $361 \pm 51$ & $491 \pm 59$ & $16.9 \pm 3.1$ & $11.5 \pm 2.1$ & $4.0 \pm 1.0$ & $4.4 \pm 0.8$ \\
\hline M1 & 38 & $369 \pm 79$ & $529 \pm 144$ & $21.1 \pm 4.4$ & $14.2 \pm 2.5$ & $5.2 \pm 1.9$ & $5.7 \pm 2.2$ \\
\hline M2 & 45 & $349 \pm 79$ & $476 \pm 71$ & $22.3 \pm 2.2$ & $15.1 \pm 4.3$ & $5.3 \pm 2.1$ & $5.7 \pm 2.1$ \\
\hline
\end{tabular}

Table 4. Animal ID and averages $( \pm \mathrm{SD}, \mathrm{n}=6$ for each dolphin) of expiratory $(\operatorname{Exp})$ and inspiratory (Insp) breath duration, respiratory flow $(\dot{V})$, and tidal volume (VT) for maximal respiratory efforts (chuffs) in water

\begin{tabular}{|c|c|c|c|c|c|c|}
\hline \multirow{2}{*}{$\begin{array}{l}\text { Animal } \\
\text { ID }\end{array}$} & \multicolumn{2}{|c|}{ Breath duration (ms) } & \multicolumn{2}{|c|}{$-\dot{V}\left(\mathrm{l} \mathrm{s}^{-1}\right)-$} & \multicolumn{2}{|c|}{- VT (l) } \\
\hline & Exp & Insp & Exp & Insp & Exp & Insp \\
\hline F1 & $411 \pm 41$ & $514 \pm 50$ & $23.8 \pm 2.8$ & $14.0 \pm 2.2$ & $5.6 \pm 0.6$ & $5.4 \pm 0.7$ \\
\hline M1 & $394 \pm 54$ & $697 \pm 106$ & $46.5 \pm 9$ & $19.2 \pm 3.3$ & $10.4 \pm 1.9$ & $10.5 \pm 1.4$ \\
\hline M2 & $420 \pm 104$ & $704 \pm 66$ & $54.0 \pm 8.3$ & $19.8 \pm 2.7$ & $10.7 \pm 1.8$ & $10.1 \pm 1.4$ \\
\hline
\end{tabular}

by Bonferroni corrected post hoc test, $2 \mathrm{df})$ in $\mathrm{F} 1\left(\mathrm{sVT}_{\text {insp }}=23 \pm 3 \mathrm{ml} \mathrm{kg}^{-1}\right.$; $\mathrm{sVT}_{\exp }=24 \pm 3 \mathrm{ml} \mathrm{kg}^{-1} ; \mathrm{s} \dot{V i n s p}=61 \pm$ $10 \mathrm{ml} \mathrm{s}^{-1} \mathrm{~kg}^{-1} ; \mathrm{s} \dot{V} \exp =103 \pm 12 \mathrm{ml} \mathrm{s}^{-1}$ $\mathrm{kg}^{-1}, \mathrm{p}<0.01$ for all), as compared with the 2 males $\left(\mathrm{sVT}_{\text {insp }}=56-57 \mathrm{ml} \mathrm{kg}^{-1}\right.$; $\mathrm{sVT}_{\exp }=56-60 \mathrm{ml} \mathrm{kg}{ }^{-1} ; \mathrm{s} \dot{V}$ insp = 103-112 $\mathrm{ml} \mathrm{s}^{-1} \mathrm{~kg}^{-1} ; \mathrm{s} \dot{V} \exp =$ 250-305 $\mathrm{ml} \mathrm{s}^{-1} \mathrm{~kg}^{-1}$ ).

For M1 or F1, neither $\mathrm{FEF}_{25 \%-75 \%}$ nor $\% \mathrm{VC}_{\mathrm{PEF}}$ changed systematically

(exp) breath durations (insp $=359 \pm 67 \mathrm{~ms}$, $\exp =498$ $\pm 96 \mathrm{~ms}), \dot{V}\left(\operatorname{insp}=13.6 \pm 3.31 \mathrm{~s} \mathrm{~s}^{-1}, \exp =20.1 \pm 4.01\right.$ $\left.\mathrm{s}^{-1}\right)$, or VT (insp $=5.3 \pm 1.8 \mathrm{l}$, $\exp =4.8 \pm 1.8 \mathrm{l}$ ) between dolphins with or without pulmonary disease ( $p>0.1$ for all, multivariate GLM; Table 3).

For the 3 maximal breathing efforts for each trial (chuffs, $\mathrm{n}=18$ for each dolphin), there were no systematic changes over the experimental period for breath duration, $\dot{V}$, or VT for any dolphin (p > 0.1). However, the average mass-specific VT (sVT, ml $\mathrm{kg}^{-1}$ ) and $\dot{V}\left(\mathrm{~s} \dot{V}, \mathrm{ml} \mathrm{s}^{-1} \mathrm{~kg}^{-1}\right)$ for forced breaths were significantly lower (least squares regression followed with repeated trials ( $p>0.05$ for all tests; Fig. 1). For $\mathrm{M} 2$, on the other hand, both $\mathrm{FEF}_{25 \%-75 \%}\left(\chi^{2}=10.2\right.$, $1 \mathrm{df}, \mathrm{p}<0.01)$ and $\% \mathrm{VC}_{\mathrm{PEF}}\left(\chi^{2}=18.6,1 \mathrm{df}, \mathrm{p}<0.001\right)$ decreased by 27 and $52 \%$, respectively, for dates when this dolphin was diagnosed with pneumonia (Fig. 1). For the dolphins with pulmonary disease (M2 and F1), $\mathrm{FEF}_{25 \%-75 \%}\left(\chi^{2}=20.5,1 \mathrm{df}, \mathrm{p}<0.001\right)$ and $\% \operatorname{VC}_{\mathrm{PEF}}\left(\chi^{2}=22.8,1 \mathrm{df}, \mathrm{p}<0.001\right)$ were 36 and $61 \%$ lower, respectively, compared with the healthy animal.

The flow-volume relationship was visually evaluated for the 3 maximal respiratory efforts of each trial
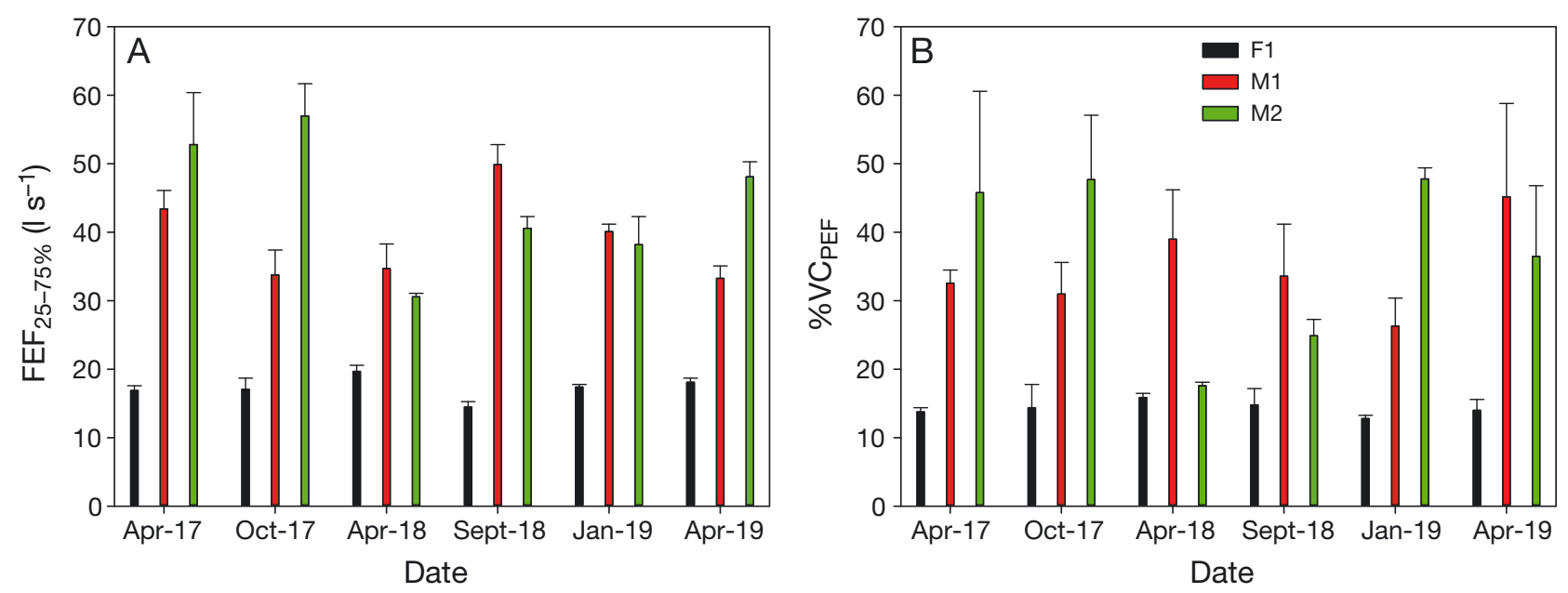

Fig. 1. Average $( \pm \mathrm{SD})$ of $(\mathrm{A})$ mid forced expiratory flow $\left(\mathrm{FEF}_{25} \%-75 \%\right)$ and $(\mathrm{B})$ the percent of the expired vital capacity at the peak expiratory flow ( $\% \mathrm{VC}_{\mathrm{PEF}}$ ) obtained from the 3 maximal respiratory efforts (chuffs) performed in water between April 2017 and April 2019 from a dolphin diagnosed with pulmonary fibrosis (F1), a healthy dolphin (M1), and a dolphin diagnosed with pneumonia in January 2018 and with active disease in April 2018 (M2) 
in water. In the dolphin with pulmonary fibrosis (F1), the flow-volume relationship showed a consistent shape, reduction in $\mathrm{VC}$, and flow abnormalities during all testing periods (Fig. 2A). In the healthy male dolphin (M1), the shape was consistent between trials and indicated no flow or volume limitations (Fig. 2B). A normal flow-volume relationship was seen in
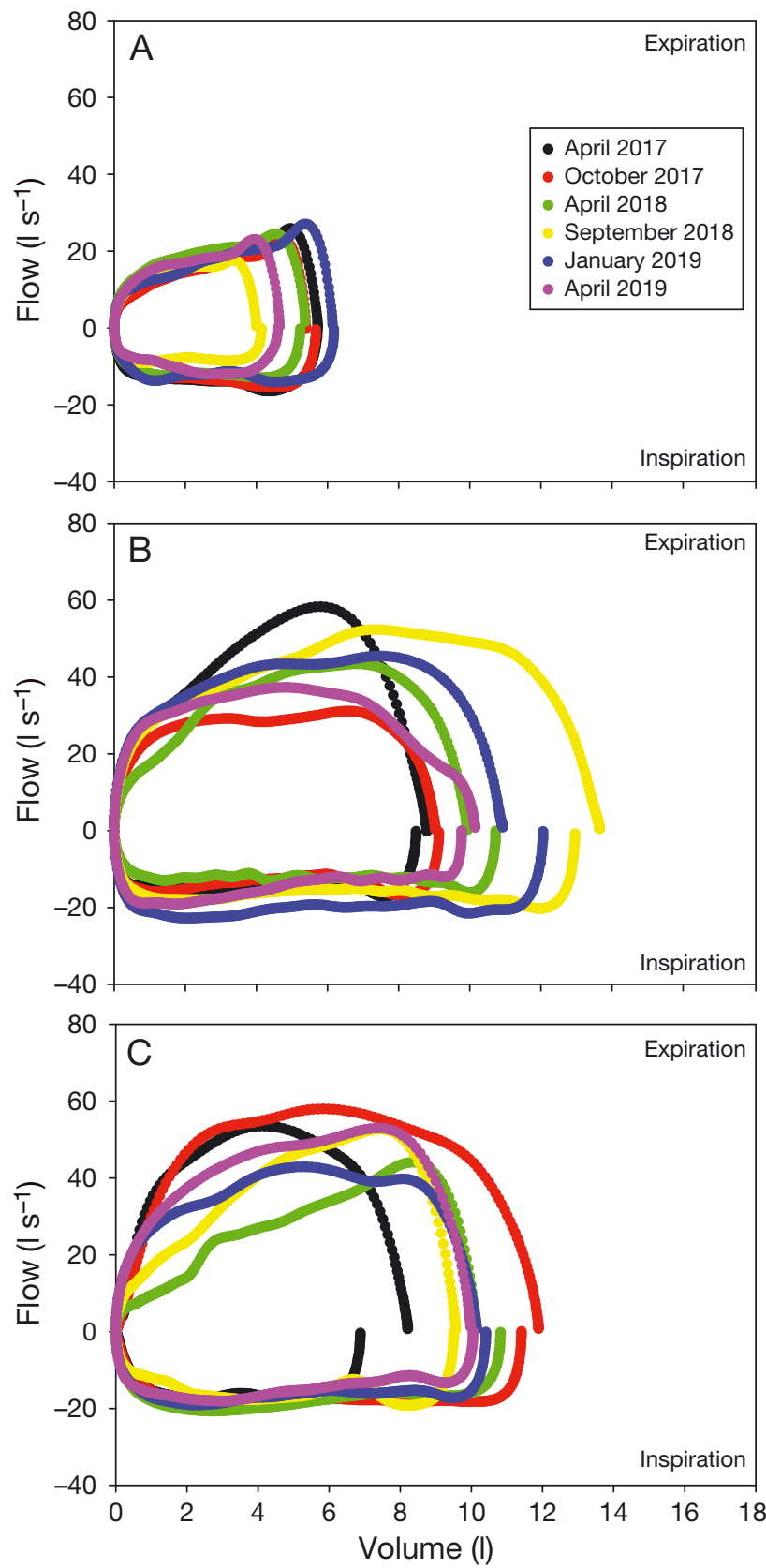

Fig. 2. Flow-volume data from forced respirations in water from (A) a dolphin diagnosed with pulmonary fibrosis (F1), (B) a healthy dolphin (M1), and (C) a dolphin diagnosed with pneumonia in January 2018 and with active disease in April 2018 (M2). Positive flow values are expiration and negative values are inspiration
M2 during the trials in 2017, when the dolphin was healthy, but flow limitations appeared during the testing in April 2018, followed by a gradual recovery towards a normal shape during 2019 (Fig. 2C).

\subsection{Spirometry on land (beached)}

In October 2017 and April 2018, 2 animals (M1 and M2) were beached for a physical examination, and pulmonary function testing was opportunistically performed during spontaneous breathing. Three breaths per trial were used to evaluate $\mathrm{FEF}_{25 \%-75 \% \text {, }}$ $\% \mathrm{VC}_{\mathrm{PEF}}$, and the flow-volume relationship. For M1, there were no significant changes in $\mathrm{FEF}_{25 \%-75 \%}$ or $\% \mathrm{VC}_{\mathrm{PEF}}$, and the shape of the flow-volume relationship was consistent during spontaneous breaths while beached and in water (Figs. 3 \& 4). When M2 beached, the $\% \operatorname{VC}_{\mathrm{PEF}}\left(\chi^{2}=13.1,1 \mathrm{df}, \mathrm{p}<0.001\right)$ significantly decreased by $49 \%$ in April 2018, at which time this animal was diagnosed with pneumonia (Fig. 3). For the same dolphin, the flow-volume relationship appeared normal while in water, but abnormalities were apparent during spontaneous breaths while beached (Fig. 4).

\section{DISCUSSION}

Pulmonary function testing is a simple and noninvasive method to study respiratory physiology in

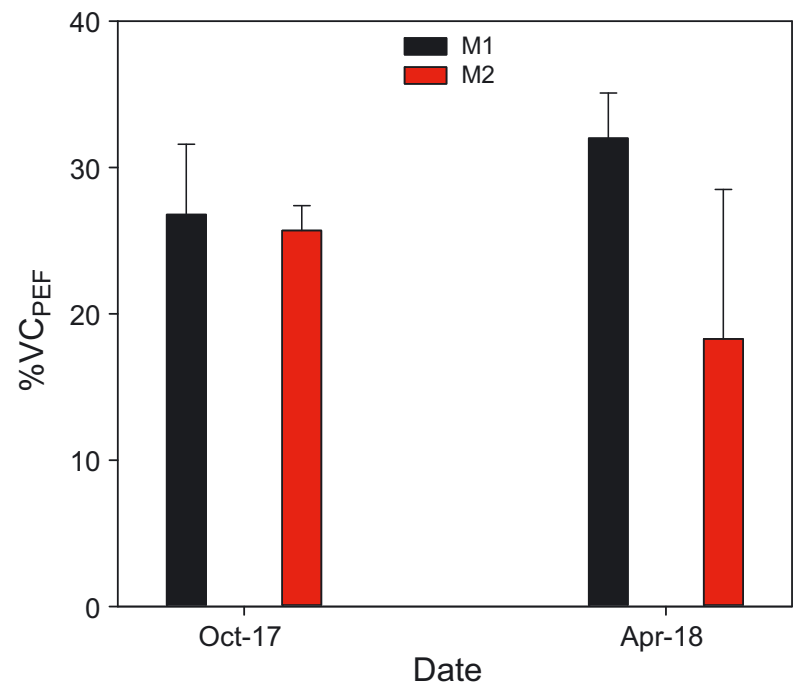

Fig. 3. Percent of the expired vital capacity at the peak expiratory flow $\left(\% \mathrm{VC}_{\mathrm{PEF}}\right)$ from 3 voluntary breaths while beached (October 2017 and April 2018) from a healthy dolphin (M1) and a dolphin diagnosed with pneumonia in January 2018 and with active disease in April 2018 (M2) 


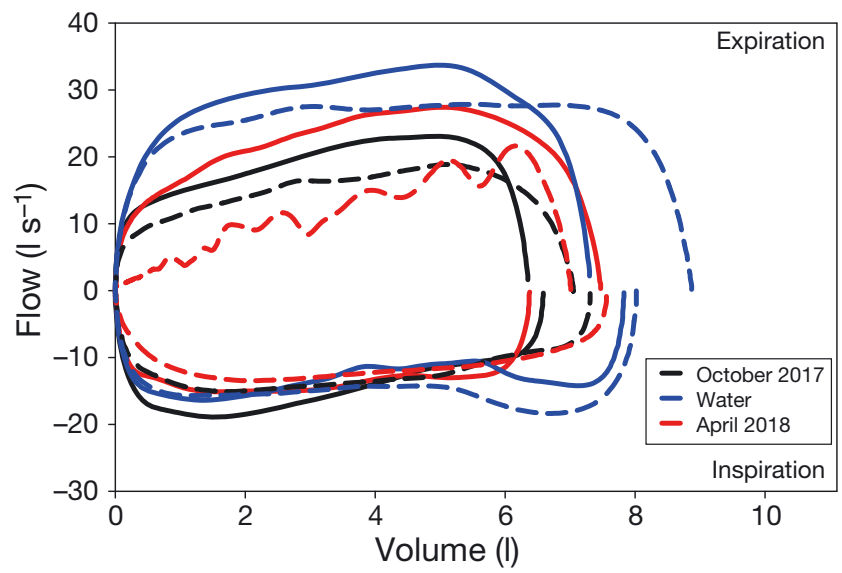

Fig. 4. Flow-volume data of voluntary breaths while beached (black and red lines) and in water (blue lines) from a healthy dolphin (M1, solid line) and a dolphin diagnosed with pneumonia in January 2018 and with active disease in April 2018 (M2, dashed line). Positive flow values are expiration and negative values are inspiration

voluntarily participating cetaceans (Olsen et al. 1969, Kooyman \& Cornell 1981, Fahlman et al. 2015, 2017, 2019a). These methods are also commonly used in humans to diagnose a variety of pulmonary diseases (Crapo et al. 1982, Miller et al. 2005) and have been adapted for use in some terrestrial mammals (e.g. cats, dogs, and horses) (Willoughby \& McDonell 1979, McKiernan \& Johnson 1992, Hoffman \& Mazan 1999, Herholz et al. 2002, Hoffman 2002, Balakrishnan \& King 2014). For these reasons, pulmonary function testing has been considered a potentially useful adjunctive diagnostic tool in veterinary medicine to assess lung health in marine mammals (Van Elk et al. 2001, Gans 2013). In this pilot study, we evaluated pulmonary function testing in 3 bottlenose dolphins as an adjunctive diagnostic tool to assess respiratory health. The pulmonary function testing was compared with standard veterinary methods, e.g. thoracic radiographs, blood count, and blow cytology and culture, to evaluate pulmonary health. Our preliminary results suggest that pulmonary function testing could have the potential to aid in diagnosis, evaluate functional changes, and assess treatment efficacy in managed care dolphins trained to exhale maximally. In addition, further research is necessary to verify if this tool may also provide adjunctive diagnostic information in stranded wild dolphins while breathing spontaneously.

Pulmonary parenchymal disease (usually pneumonia) in cetaceans is predominantly inflammatory in nature, with underlying infection identified as the likely initiating cause in many cases (McBain 2001, Sweeney \& Reddy 2001, Venn-Watson et al. 2012). As such, indicators of inflammation are generally detected in routine haematology, serum chemistry analysis, and blow samples from forceful expiration (Dierauf \& Gulland 2001, Sweeney \& Reddy 2001). Digital radiography is a modality readily available and frequently used to assess dolphins for evidence of pulmonary disease in many marine mammal facilities in the USA. While CT is considered the medical gold standard for radiological evaluation of the lung parenchyma (Ivančić et al. 2014), assessment using CT was not logistically feasible. The female dolphin (F1) showed no signs of active inflammatory disease on blow cytology, but showed a decreased serum iron and abnormal radiograph findings interpreted as pulmonary fibrosis throughout the study. For M1, no abnormal clinical values were documented with haematology, clinical chemistry, or blow cytology throughout the study. However, in January 2019, an emerging abnormal pattern was detected through radiography which was interpreted as a possible low degree of pneumonia that resolved by March 2019. Clinical values for M2 were within the normal range, except the erythrocyte sedimentation rate, which was significantly elevated when the animal was diagnosed with pneumonia through radiography. Possible methods to classify the type of pneumonia include fungal immunodiffusion assay, BAL, or bronchoscopy (Reidarson et al. 1998), but none of these clinical tests were performed. This highlights the limitation of routine diagnostic methods, which appear not to be sensitive in all cases. Thus, complementary techniques to evaluate functional changes in pulmonary health should be considered.

While standard pulmonary function testing does not provide aetiologic information about the disease, it quantifies the degree of severity and the progression of the respiratory system disorder, and, in some cases, is able to define where in the respiratory airways the disease is located (Balakrishnan \& King 2014). For example, in human medicine, maximal inspiratory efforts are used to assess respiratory disease of the upper airways, while expiratory efforts help identify dysfunction of the lower airways. In the present study, operant conditioning assured data collection from maximal expiratory efforts. Therefore, we evaluated these maximal expiratory manoeuvres based on methods developed in human medicine (Miller et al. 2005, García-Río et al. 2013), but modified for the respiratory function in dolphins, to assess flow and volume limitations associated with disease in the lower airways of the respiratory system. In human medicine, volume-related indices, e.g. the maximal volume of exhaled air (forced vital capacity, $\mathrm{FVC}$ ) and the forced expiratory volume in the first 
second $\left(\mathrm{FEV}_{1}\right)$, are important to assess pulmonary health in the lower airways, where severe obstructive or restrictive respiratory disease results in a decrease in both indices (García-Río et al. 2013). However, cetaceans have high expiratory flows at all lung volumes (Fig. 2B), a VC that is close to total lung capacity, and breath durations of less than $1 \mathrm{~s}$ (Olsen et al. 1969, Kooyman \& Sinnett 1979, Kooyman \& Cornell 1981, Fahlman et al. 2015, 2017, 2019a). Consequently, the traits of the cetacean respiratory system make it difficult to assess lung health through $\mathrm{FEV}_{1}$. On the other hand, while VT during forced breaths can be used as an estimate of FVC, no differences were detected in VT throughout the experimental period in any of the dolphins. However, the sVT during forced breaths in F1 was considerably lower than in M1 and M2 (see Section 3.2). This could be a consequence of the reduction in $\mathrm{VC}$ due to pulmonary fibrosis (restrictive disease), and/or be related to differences in the respiratory functionality due to gender or age, as commonly found in humans (Sharma \& Goodwin 2006, Ruivo et al. 2009). Whether this is a sign of pulmonary disease, age, or gender cannot be determined with our limited data set; baseline values of healthy dolphins over a range of ages would be needed for comparison.

Other standard flow-related indices used in human medicine to assess pulmonary health in the lower airways include $\mathrm{FEF}_{25 \%-75 \%}$ and PEF, where obstructive or restrictive disease results in a decrease in both indices (García-Río et al. 2013). $\mathrm{FEF}_{25 \%-75 \%}$ provides information about flow values in the mid part of the forced expiration. Furthermore, $\mathrm{FEF}_{25 \%-75 \%}$ details the mechanical function of the lungs through evaluation of the flow-volume relationship across different volumes. We therefore hypothesized that this index would provide valuable information about lung health in the dolphins. The PEF index, on the other hand, only gives information about the maximal expiratory flow during a forced manoeuvre. Assuming that the expiratory $\dot{V}$ during forced breaths provides an estimate of PEF, we detected no systematic changes in this lung function index for any of the dolphins during the experimental period, but lower mass-specific values were seen in F1 compared with M1 and M2, which could be also related with the respiratory disease, gender or age. In addition, the PEF can be reached at both high and medium volumes in healthy dolphins (Fig. 2B). However, in dolphins with respiratory disease, the PEF only occurred at high volumes during the forced expiratory manoeuvre, with the flow then rapidly decreasing with reduced lung volume (Fig. 2A,C). We therefore used the $\% \mathrm{VC}_{\mathrm{PEF}}$ as another index for pulmonary disease detection, where a lower percentage of expired volume in the PEF is expected in animals with lung disease.

Our preliminary data suggest that pulmonary function testing could be a useful method to assess respiratory health through evaluation of the functional capacity from forced breaths in dolphins under managed care (Figs. 1 \& 2). For the female diagnosed with pulmonary fibrosis (F1), neither index changed temporally, but both indices were lower as compared with the values in the healthy dolphins (Fig. 1), similar to the results for sVT and $\mathrm{s} \dot{V}$ (see Section 3.2). We propose that the consistent reduction in $\mathrm{FEF}_{25 \%-75 \%}$, $\% \mathrm{VC}_{\mathrm{PEF}}$, and forced VT and $\dot{V}$ corresponded well with the radiographical findings, as chronic fibrosis is a pulmonary restrictive disease that reduces VC. Additionally, the shape of the flow-volume relationship for F1 also suggested obstructive disease, where the PEF occurred at high lung volume and the $\dot{V}$ rapidly decreased with lung volume (Fig. 2A).

For M1, none of the indices changed throughout the study, even during the time (January 2019) when the radiographs indicated unstructured interstitial changes interpreted as a low degree of pneumonia. The flow-volume relationship for M1 indicated a healthy lung that could maintain high flow over the entire lung volume (Fahlman et al. 2017) and no evidence of pulmonary disease (Fig. 2B). Additionally, no changes in the clinical routine health assessment were found, and the pneumonia quickly resolved. Therefore, we suggest that the emerging pneumonia was of low severity and did not alter lung function detectable through PFT.

For M2, both $\mathrm{FEF}_{25 \%-75 \%}$ and $\% \mathrm{VC}_{\mathrm{PEF}}$ decreased substantially from 2017 until April 2018, at which time the dolphin had been diagnosed with pneumonia. Both $\mathrm{FEF}_{25 \%-75 \%}$ and \% $\mathrm{VC}_{\mathrm{PEF}}$ then increased in September 2018 and January 2019, suggestive of recovery (Fig. 1), which was confirmed by radiography. The flow-volume relationship for M2 indicated an obstructive pattern in April 2018, and progressive recovery during 2019 (Fig. 2C). However, the pneumonia (restrictive disease) did not cause a reduced $\mathrm{VC}$ for $\mathrm{M} 2$, and parenchymal inflammation (e.g. pneumonia) is commonly related to concomitant obstructive diseases in the respiratory airways. Thus, while both F1 and M2 were diagnosed with restrictive disease through routine diagnostic methods, the lung function testing also suggested lower airway obstruction in both dolphins. Therefore, pulmonary function testing added diagnostic information about the type and location of the disease. 
In human medicine, respiratory disease is evaluated by spirometry through maximal respiratory efforts. In small terrestrial mammals, or in human paediatric medicine, methods have been developed to identify airway obstruction during spontaneous breathing, where reliable cooperation of the patient to perform maximal respiratory efforts is difficult (Abramson et al. 1982, Balakrishnan \& King 2014). The tidal breathing flow-volume loop (TBFVL) test has been develop to evaluate flow obstruction in human infants (Abramson et al. 1982). This method has also been tested in small domestic animals (McKiernan \& Johnson 1992, Balakrishnan \& King 2014). It has been suggested that the sensitivity of the TBFVL test could be enhanced by increasing the external pressure on the chest wall in patients that are not able to perform maximal respiratory efforts (Abramson et al. 1982). While dolphins are beached, the external pressure on the chest is increased due to their weight. For M1 and M2 when healthy and spontaneously breathing, there was a decrease in VC and a steeper slope of the flow-volume relationship while beached as compared to when in water (Fig. 4). Thus, the extra pressure on the chest could lead to an increase in the respiratory effort, which resulted in the observed changes for both dolphins while healthy. Between beached testing dates, there were no changes in any of the PFT indices and the flow-volume relationship for M1. For M2, on the other hand, there was a significant decrease in the $\% \mathrm{VC}_{\mathrm{PEF}}$ (Fig. 3), and changes in the slope of the flow-volume relationship consistent with flow abnormalities for the trial date when the animal had been diagnosed with pneumonia (Fig. 4). We suggest that the combination of respiratory effort and pulmonary disease increased the respiratory limitation in M2, resulting in the observed results. These pilot data suggest that the \% $\mathrm{VC}_{\mathrm{PEF}}$ index could also be sensitive during spontaneous breaths with increased respiratory effort while beached. For example, when M2 contracted pneumonia, the PEF reached its maximum at the beginning of the expiration, similarly to forced breaths in water. On the other hand, $\mathrm{FEF}_{25 \%-75 \%}$ is related to the slope of the flow-volume relationship during the expiration. Therefore, we suggest that the steeper slope of the flow-volume relationship due to the additional pressure on the chest while beached makes it difficult to evaluate lung disease through $\mathrm{FEF}_{25 \%-75 \%}$ while spontaneously breathing on land, as the slopes when M2 was healthy and when diagnosed with pneumonia were similar (Fig. 4). Consequently, extensive data from other clinical cases are necessary for a deeper understanding about the relation between $\% \mathrm{VC}_{\mathrm{PEF}}$,

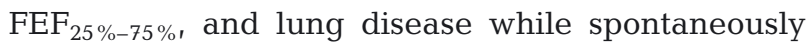
breathing on land.

Pulmonary function testing has been suggested as a non-invasive method to assess lung health in marine mammal veterinary medicine. The methodology is still being developed, requires post-processing, and offers some challenges when applied to trained animals. For example, placement of the mask over the blow hole (or nostrils in pinnipeds) may cause a certain amount of discomfort. Additionally, the training itself may cause a bias through conditioning the respiratory manoeuvres, which is difficult to evaluate. Although desensitization helps improve comfort and repeatability between testing dates in the pulmonary function values, the same is not true for wild individuals. Some researchers consider results from animals under human care to have limited value. However, certain information is nearly impossible to collect from wild populations, where it is logistically and ethically challenging to perform controlled studies. Studying physiology and function in animals under managed care includes access to complete medical histories, as well as the ability to perform more comprehensive diagnostics than is possible with wild animals. The animals can be trained to participate voluntarily for baseline data collection with minimal stress and to cooperate to perform certain manoeuvres, e.g. maximal respiratory efforts made in cetaceans or pinnipeds (Fig. 1; Kerem et al. 1975, Kooyman \& Cornell 1981, Fahlman et al. 2015, 2019a, 2020, Fahlman \& Madigan 2016). Such cooperation is possible with trained animals, but not in wild populations (Fahlman et al. 2018a,b).

Our preliminary results presented here indicate that spirometry has the potential to improve and provide additional information about the type (obstructive or restrictive) and location (lower airways) of the pulmonary disease. While pulmonary function testing development would require training to generate maximal respiratory efforts for dolphins in water, we additionally suggest that this non-invasive method should be studied to define or characterize respiratory health in stranded cetaceans while breathing spontaneously. Our results highlight the importance of studying trained animals under managed care, where development and validation of new equipment can be performed under controlled situations before being applied to wild animals. Therefore, further research with the knowledge gained in the present study is necessary to validate the technique: characterization of lung function indices, classification of the flow-volume relationship related to ob- 
structive and restrictive pulmonary diseases, and determination of reference values for healthy animals of different gender and age (young, mature, and elderly). We conclude that development of pulmonary function testing in marine mammals could provide a simple, portable, and non-invasive diagnostic tool which would help asses respiratory health and temporal changes in both dolphins under human care and in wild stranded animals.

Acknowledgements. A special thanks to all the trainers and staff at Siegfried and Roy's Secret Garden and Dolphin Habitat, who made this study possible. We thank 3 anonymous referees who provided valuable constructive comments that helped improve the article. Funding for this project was provided by the Office of Naval Research (ONR YIP Award No. N000141410563). The Mirage provided travel support and in-kind support of animals, crew, and access to resources. We also thank Dolphin Quest which has been instrumental in helping to develop the equipment and methods used to perform Pulmonary Function Testing in dolphins.

\section{LITERATURE CITED}

Abramson AL, Goldstein MN, Stenzler A, Steele A (1982) The use of the tidal breathing flow volume loop in laryngotracheal disease of neonates and infants. Laryngoscope 92:922-926

Baker JR (1992) Causes of mortality and parasites and incidental lesions in dolphins and whales from British waters. Vet Rec 130:569-572

Balakrishnan A, King LG (2014) Updates on pulmonary function testing in small animals. Vet Clin North Am Small Anim Pract 44:1-18

Bogomolni AL, Pugliares KR, Sharp SM, Patchett K and others (2010) Mortality trends of stranded marine mammals on Cape Cod and southeastern Massachusetts, USA, 2000 to 2006. Dis Aquat Org 88:143-155

Crapo RO (1994) Pulmonary-function testing. N Engl J Med 331:25-30

Crapo RO, Morris AH, Clayton PD, Nixon CR (1982) Lung volumes in healthy nonsmoking adults. Bull Eur Physiopathol Respir 18:419-425

Dierauf LA, Gulland FMD (eds) (2001) CRC handbook of marine mammal medicine, $2^{\text {nd }}$ edn. CRC Press, Boca Raton, FL

Fahlman A, Madigan J (2016) Respiratory function in voluntary participating Patagonia sea lions (Otaria flavescens) in sternal recumbency. Front Physiol 7:528

Fahlman A, Loring SH, Levine G, Rocho-Levine J, Austin T, Brodsky M (2015) Lung mechanics and pulmonary function testing in cetaceans. J Exp Biol 218:2030-2038

Fahlman A, Moore MJ, Garcia-Parraga D (2017) Respiratory function and mechanics in pinnipeds and cetaceans. J Exp Biol 220:1761-1773

Fahlman A, Brodsky M, Wells R, McHugh K and others (2018a) Field energetics and lung function in wild bottlenose dolphins, Tursiops truncatus, in Sarasota Bay Florida. R Soc Open Sci 5:171280

Fahlman A, McHugh K, Allen J, Barleycorn A and others (2018b) Resting metabolic rate and lung function in wild offshore common bottlenose dolphins, Tursiops truncatus, near Bermuda. Front Physiol 9:886

*Fahlman A, Epple A, Garcia-Párraga DG, Robeck T, Haulena M, Piscitelli-Doshkov M, Brodsky M (2019a) Characterizing respiratory capacity in belugas (Delphinapterus leucas). Respir Physiol Neurobiol 260:63-69

Fahlman A, Miedler S, Rocho-Levine J, Jabois A and others (2019b) Re-evaluating the significance of the dive response during voluntary surface apneas in the bottlenose dolphin, Tursiops truncatus. Sci Rep 9:8613

Fahlman A, Meegan J, Borque Espinosa A, Jensen ED (2020) Pulmonary function and resting metabolic rates in trained California sea lions (Zalophus californianus) on land and in water. Aquat Mamm 46:67-79

Gans S (2013) Lung function measurements using spirometry in small cetaceans: Tursiops truncatus and Phocoena phocoena. MSc thesis, University of Utrecht

García-Río F, Calle M, Burgos F, Casan P and others (2013) Spirometry. Arch Bronconeumol 49:388-401

* Herholz C, Straub R, Luthi S, Moens Y, Imhof A, Busato A (2002) Validity of pulmonary function indices derived from the volumetric capnogram in horses with recurrent airway obstruction (RAO). Res Vet Sci 72:141-146

Hoffman AM (2002) Clinical application of pulmonary function testing in horses. In: Lekeux P (ed) Equine respiratory diseases. International Veterinary Information Service, Ithaca, NY

Hoffman AM, Mazan MR (1999) Programme of lung function testing horses suspected with small airway disease. Equine Vet Educ 11:322-328

Howard EB, Britt JO, Matsumoto GK, Itahara R, Nagano CN (1983) Bacterial diseases. In: Howard EB (ed) Pathobiology of marine mammal diseases. CRC Press, Boca Raton, FL, p 69-118

* Ivančić M, Solano M, Smit CR (2014) Computed tomography and cross-sectional anatomy of the thorax of the live bottlenose dolphin (Tursiops truncatus). Anat Rec 297: 901-915

Johnson WR, Torralba M, Fair PA, Bossart GD, Nelson KE, Morris PJ (2009) Novel diversity of bacterial communities associated with bottlenose dolphin upper respiratory tracts. Environ Microbiol Rep 1:555-562

Kerem DH, Kylstra JA, Saltzman HA (1975) Respiratory flow rates in the sea lion. Undersea Biomed Res 2:20-27

Kooyman GL, Cornell LH (1981) Flow properties of expiration and inspiration in a trained bottle-nosed porpoise. Physiol Zool 54:55-61

Kooyman GL, Sinnett EE (1979) Mechanical properties of the harbor porpoise lung, Phocoena phocoena. Respir Physiol 36:287-300

*Martony ME, Ivančić M, Gomez FM, Meegan JM and others (2017) Establishing marginal lymph node ultrasonographic characteristics in healthy bottlenose dolphins (Tursiops truncatus). J Zoo Wildl Med 48:961-971

McBain JF (2001) Cetacean medicine. In: Dierauf LA, Gulland FMD (eds) CRC handbook of marine mammal medicine, $2^{\text {nd }}$ edn. CRC Press, Boca Raton, FL, p 895-908

*McKiernan BC, Johnson LR (1992) Clinical pulmonary function testing in dogs and cats. Vet Clin North Am Small Anim Pract 22:1087-1099

Miller MR, Hankinson J, Brusasco V, Burgos F and others (2005) Standardisation of spirometry. Eur Respir J 26: 319-338

Olsen CR, Hale FC, Elsner R (1969) Mechanics of ventilation in the pilot whale. Respir Physiol 7:137-149 
Reidarson TH, Harrell JH, Rinaldi MG, McBain J (1998) Bronchoscopic and serologic diagnosis of Aspergillus fumigatus pulmonary infection in a bottlenose dolphin (Tursiops truncatus). J Zoo Wildl Med 29:451-455

Rozanski EA, Hoffman AM (1999) Pulmonary function testing in small animals. Clin Tech Small Anim Pract 14: $237-241$

Ruivo S, Viana P, Martins C, Baeta C (2009) Effects of aging on lung function. A comparison of lung function in healthy adults and the elderly. Rev Port Pneumol 15:629-653

Sharma G, Goodwin J (2006) Effect of aging on respiratory system physiology and immunology. Clin Interv Aging 1: 253-260

Smith CR, Solano M, Lutmerding BA, Johnson SP and others (2012) Pulmonary ultrasound findings in a bottlenose dolphin Tursiops truncatus population. Dis Aquat Org 101:243-255

Sweeney JC, Reddy ML (2001) Cetacean cytology. In: Dierauf LA, Gulland FMD (eds) CRC handbook of marine

Editorial responsibility: Stephen Raverty, Abbotsford, British Columbia, Canada mammal medicine, $2^{\text {nd }}$ edn. CRC Press, Boca Raton, FL, p 437-446

Sweeney JC, Ridgway SH (1975) Common diseases of small cetaceans. J Am Vet Med Assoc 167:533-540

Van Bonn W, Jensen ED, Brook F (2001) Radiology, computed tomography and magnetic resonance imaging. In: Dierauf LA, Gulland FMD (eds) CRC handbook of marine mammal medicine, $2^{\text {nd }}$ edn. CRC Press, Boca Raton, FL, p 557-591

*Van Elk CE, Epping N, Gans SJ (2001) Pulmonary function measurements in dolphins using capnography. Vet Rec 149:308-309

Venn-Watson S, Daniels R, Smith C (2012) Thirty year retrospective evaluation of pneumonia in a bottlenose dolphin Tursiops truncatus population. Dis Aquat Org 99: 237-242

*Willoughby RA, McDonell WN (1979) Pulmonary function testing in horses. Vet Clin North Am Large Anim Pract 1: 171-196

Submitted: March 21, 2019; Accepted: December 19, 2019 Proofs received from author(s): January 31, 2020 